\title{
IIIness of Immune Reconstitution: Recognition and Management
}

\author{
Edward M. Gardner, MD, and Elizabeth Connick, MD*
}

\author{
Address \\ *D ivision of Infectious D iseases, University of C olorado H ealth Sciences \\ Center, 4200 East 9th A venue, Box B168, Denver, C 0 80262, USA. \\ E-mail: liz.connick@uchsc.edu \\ Current Infectious Disease Reports 2004, 6:483-493 \\ Current Science Inc. ISSN 1523-3847 \\ Copyright @ 2004 by Current Science Inc.
}

Some individuals who initiate highly active antiretroviral therapy (HAART) develop new or worsening opportunistic infections or malignancies despite improvements in surrogate markers of HIV-1 infection. These events of paradoxical clinical worsening, also known as immune reconstitution syndromes (IRS), are increased in individuals with prior opportunistic infections or low CD4+ T-cell nadirs. They are thought to result from reconstitution of the immune system's ability to recognize pathogens or tumor antigens that were previously present, but clinically asymptomatic. There is no consensus regarding the diagnostic criteria or pathogenesis of IRS. Knowledge of their presentation and treatment is largely based on case reports. W ith the introduction of HAART into resource-limited settings, it is likely that significantly more and distinct forms of IRS will be observed. Prospective studies of the incidence and treatment of IRS in multiple settings are critical to better understand their pathogenesis and optimal management.

\section{Introduction}

The introduction of potent combination antiretroviral therapy in the mid-1990s has resulted in remarkable dedines in morbidity and mortality associated with HIV-1 infection in the developed world [1]. Clinical benefits have correlated with increases in CD4+T-cell counts and decreases in plasma HIV-1 RNA concentrations and, with excellent adherence to antiretroviral medications, the benefits appear long-lived. However, some individuals who initiate highly active antiretroviral therapy (HAART) develop new or recurrent opportunistic infections despite improvements in CD4+T-cell counts and/or decreases in plasma viral loads. In some instances, the presentation of these illnesses has been distinctly different from that of opportunistic infections of AIDS patients in the preHAART era, often associated with a pronounced inflammatory response. It is believed that these illnesses, which have been referred to as immune reconstitution syndromes
(IRS) [2], immune restoration diseases [3••], or immune reconstitution inflammatory syndromes [4], result from restoration of the immune system's ability to recognize pathogens or tumor antigens that were present previously, but clinically occult.

The idea that enhanced immune function can cause flares or exacerbations of pre-existing diseases is not new, nor is it specific for the treatment of HIV-1 infection. Severe infectious complications after immune recovery from chemotherapy or after withdrawal of systemic steroid therapy have been described [5]. The first suggestion that IRS might result from treatment of HIV-1 infection predated HAART by several years. In 1992, unusual localized M ycobacterium avium complex (MAC) infections were observed in five AIDS patients after initiation of zidovudine monotherapy [6]. Subsequently, with the introduction of HAART, IRS have been reported in significant numbers of individuals, as reviewed previously $[2,4,7,8,9,10]$. Observations that HAART results in enhanced cellular immunity to multiple opportunistic pathogens [11-13] supported the notion that reconstitution of pathogenspecific cellular immunity may provoke IRS.

Few studies have carefully documented the incidence of infectious or inflammatory complications after initiation of HAART. In Western Australia, French et al. [3 ••] retrospectively assessed infectious complications in 132 HAART responders, defined as individuals who experienced a more than $1 \log _{10}$ decrease in plasma HIV-1 RNA concentration after starting HAART. One or more disease episodes occurred in 33 (25\%) patients within 28 weeks of commencing HAART. Most were recurrences of a previous condition and induded oral or anal herpes simplex virus (HSV) infections $(n=9)$, zoster $(n=8)$, cytomegal ovirus (CMV) retinitis $(n=6)$, MAC $(n=5)$, molluscum contagiosum and/or warts $(n=5)$, myelopathy or encephal omyelitis $(n=4)$, hepatitis $C$ virus (HCV)-related hepatitis $(n=3)$, and pulmonary M ycobacterium tuberculosis (MTB) $(n=1)$. Nadir CD4+T-cell counts were significantly lower in persons who devel oped infectious complications ( mean $=88 \mathrm{cells} / \mathrm{mm}^{3}$ ), compared with those who did not $\left(\right.$ mean $=237 \mathrm{cells} / \mathrm{mm}^{3}$ ). Sungkanuparph et al. [14] reported the results of a prospective observational trial of 60 Thai AIDS patients with a known history of cryptococcal meningitis, who were receiving secondary prophylaxis for $C$ ryptococcus and who initiated HAART. Twenty opportunistic infections were experienced by 14 (23\%) of the patients during the year 
after initiation of HAART, despite good virologic responses in most. These illnesses induded MTB $(n=8), \operatorname{MAC}(n=3)$, ayptococcal meningitis $(n=3)$, zoster $(n=3)$, toxoplasmosis $(n=2)$, and genital HSV infection $(n=1)$.

There is no consensus regarding the diagnostic criteria for IRS. Rarely, pathogen-specific immune reconstitution has been demonstrated in individuals with IRS through delayed-type hypersensitivity (DTH) skin testing or assays for pathogen-specific immune responses before and after initiation of HAART. However, such testing is neither commonly available in clinical practice nor practical to perform on a routine basis. Most experts agree that some decrease in plasma HIV-1 RNA concentration on HAART is critical to the diagnosis of IRS, al though the degree of suppression needed is unclear. In someinstances, such as MAC, unusual presentations of disease have been associated with theintroduction of HAART, and these have been considered to be diagnostic of IRS. However, in other cases, there are not clear differences in the clinical manifestations of illnesses reported as IRS and illnesses in untreated HIV-1-infected individuals, and diagnosis is primarily based on the temporal relationship between symptoms and HAART. Skepticism is warranted in many purported cases of IRS because of lack of evidence that they are a result of immune enhancement.

The types of illnesses that have been reported as IRS range from well-recognized opportunistic infections and AIDS-associated malignancies to illnesses such as Graves' disease and sarcoidosis, which historically have not been associated with HIV-1 infection (Table 1). In the following text, we review the diagnosis, management, and theories of pathogenesis of several clinical syndromes that have been reported as IRS. All IRS discussed are infections or malignancies that are increased in incidence among untreated HIV-1-infected individuals, and they are among the most frequently reported IRS in the literature Sel ection of these syndromes for review does not mean that they are all proven to be IRS. Furthermore, lack of inclusion of purported IRS does not mean that they are not genuine

\section{M ycobacterium avium Complex}

The local ized infections of MAC IRS are distinct from those of MAC infection in AIDS patients in the pre-HAART era, which usually consisted of a systemic illness characterized by fever, weight loss, anemia, and bacteremia. Of 61 cases of MAC IRS reviewed $[3 \cdot \bullet, 4,6,14-31]$, the most common clinical presentations included focal lymphadenitis (76\%) and fever (69\%). Other presentations included regional pain syndromes such as abdominal or chest pain secondary to lymphadenopathy, hypercal cemia, and extranodal disease in the liver, gastrointestinal tract, skin, lungs, muscle, central nervous system (CNS), or bone. Seventy-five percent of the MAC IRS cases reviewed were newly diagnosed, whereas $25 \%$ occurred in individuals with a prior diagnosis and history of treatment of MAC. Nadir CD4+T-cell counts were less than 50 cells $/ \mathrm{mm}^{3}$ in $83 \%$ of cases (range $=4-209$ cells $/ \mathrm{mm}^{3}$ ), but substantial increases in CD4+T-cell counts at the time of presentation were seen frequently ( median $=132 \mathrm{cell} / \mathrm{s} / \mathrm{mm}^{3}$; range $=12-474 \mathrm{cell} / \mathrm{s} / \mathrm{mm}^{3}$ ). Individuals without a previous diagnosis of MAC presented a median of 18 days after initiation of HAART, whereas those with known prior disease presented a median of 210 days after initiation of HAART. These differences in the timing of presentation may be related to the fact that all individuals with a prior history of MAC were taking antimycobacterial drugs, whereas no individuals in the newly diagnosed group were receiving them.

In a few cases of MAC IRS, reconstitution of mycobacteriaspecific lymphocyte proliferative responses has been demonstrated, whereas such responses are not found typically in individuals with disseminated MAC who are not receiving antiretroviral therapy $[6,19]$. However, most diagnoses of MAC IRS have been based on the unusual focal presentation of MAC infection, usually diagnosed by biopsy. Of biopsy specimens in which results from evaluations were reported, $81 \%$ stained positively for acid-fast bacilli (AFB), and $58 \%$ demonstrated granulomata. MAC was cultured from $64 \%$ of biopsy specimens but was found in only $32 \%$ of blood and bonemarrow cultures.

In almost all reported cases of MAC IRS, HAART was continued. In three cases, HAART was temporarily withdrawn $[4,15,19]$. In all three cases, symptoms resolved after cessation of therapy, but recurred with reinitiation of HAART $[4,15,19]$. In every case revi ewed, patients received multidrug antimycobacterial treatment regimens. Systemic steroid therapy was used in a minority of cases to manage painful regional lymphadenopathy $[3 \bullet \bullet, 24,29,30]$. Symptoms usually resolved over weeks to months in newly diagnosed and recurrent MAC IRS.

\section{M ycobacterium tuberculosis}

Worsening of clinical symptoms in MTB-infected individuals undergoing tuberculosis therapy has been observed in HIV-1 seronegative and seropositive individuals [32,33]. These paradoxical reactions are thought to be the result of enhanced MTB-specific immune responses attributed to resolution of immune suppression induced directly by tuberculosis [32], or to increased amounts of tuberculosis antigens released by dead bacilli [33]. Several studies have suggested that the incidence of paradoxical reactions is substantially increased in HIV-1-infected individuals with MTB infection who initiate HAART. Narita et al. [34] found that $12(36 \%)$ of 33 HIV-1-infected patients with MTB in a Florida state tuberculosis hospital developed paradoxical worsening after initiation of HAART. Importantly, six of seven patients with paradoxical reactions who initially had negative DTH skin test results to purified protein derivative developed positive DTH responses during HAART therapy, suggesting that MTB-specific immunity was reconstituted in these individuals. In a population of 17 HIV-1 and MTB 


\begin{tabular}{|c|c|c|c|}
\hline \multicolumn{2}{|c|}{ Infectious processes } & \multicolumn{2}{|c|}{ Noninfectious processes } \\
\hline Pathogen & Presenting symptoms & Disease & Presenting symptoms \\
\hline $\begin{array}{l}\text { Mycobacterium avium complex } \\
{[3 \cdot \bullet, 4,6,14-31]}\end{array}$ & See text & Kaposi's sarcoma $[4,118-120]$ & See text \\
\hline $\begin{array}{l}\text { M ycobacterium tuberculosis } \\
{[4,14,24,26,34,35,36 \cdot \bullet, 37-47]}\end{array}$ & See text & Lymphoma [127] & $\begin{array}{l}\text { Fever, weight loss, } \\
\text { lymphadenopathy, } \\
\text { mass, bone pain }\end{array}$ \\
\hline Mycobacterium xenopi [24] & Fever, sweats, cough & Sarcoidosis $[7,128]$ & $\begin{array}{l}\text { Cutaneo us sarcoidosis, } \\
\text { erythema no dosum, } \\
\text { abnormal chest } \\
\text { computed tomography }\end{array}$ \\
\hline Mycobacterium leprae [126] & $\begin{array}{l}\text { Skin plaques with } \\
\text { paresthesias }\end{array}$ & G uillain-Barré syndrome [129] & $\begin{array}{l}\text { Leg weakness, fall, } \\
\text { dysphagia, urinary } \\
\text { hesitancy, conjunctivitis }\end{array}$ \\
\hline $\begin{array}{l}\text { Cryptococcus neoformans } \\
{[4,28,48-59]}\end{array}$ & See text & Graves' disease $[3 \cdot \bullet, 4,130,131]$ & Thyrotoxicosis \\
\hline Pneumocystis jirovecii $[4,28,60-63]$ & See text & A lopecia universalis [131] & Total body hair loss \\
\hline Histoplasma capsulatum [132] & $\begin{array}{l}\text { Papulo-pustular rash, } \\
\text { pneumonia }\end{array}$ & Tattoo intolerance [133] & $\begin{array}{l}\text { Itching and scabbing } \\
\text { of tattoos }\end{array}$ \\
\hline Candida albicans [28] & Eso phageal candidiasis & & \\
\hline $\begin{array}{l}\text { Cytomegalovirus } \\
{[4,25,28,59,66,67,69-81]}\end{array}$ & See text & & \\
\hline JC virus $[82-90]$ & See text & & \\
\hline Hepatitis B virus [96-101] & See text & & \\
\hline Hepatitis C virus $[95,102,103]$ & See text & & \\
\hline $\begin{array}{l}\text { Varicella zoster virus } \\
{[4,28,106-111]}\end{array}$ & See text & & \\
\hline Human papilloma virus [112-114] & See text & & \\
\hline Herpes simplex virus $[3 \cdot \bullet, 134]$ & $\begin{array}{l}\text { O ral and genital ulcers, } \\
\text { encephalitis, myelopathy }\end{array}$ & & \\
\hline Parvovirus B19 [135] & $\begin{array}{l}\text { Clumsiness, dysphasia, } \\
\text { apraxia }\end{array}$ & & \\
\hline Bartonella henselae [136] & $\begin{array}{l}\text { Splenitis, abdominal } \\
\text { pain, fever }\end{array}$ & & \\
\hline $\begin{array}{l}\text { Demodex folliculorum, } \\
\text { Pityrosporon [137] }\end{array}$ & Inflammatory folliculitis & & \\
\hline Toxoplasma gondii [28] & Cerebral toxoplasmosis & & \\
\hline Leishmania major [125] & U veitis & & \\
\hline Leishmania infantum [138] & Visceral leishmaniasis & & \\
\hline Schistosomiasis [139] & Eosinophilia & & \\
\hline Microsporidiosis [140] & $\begin{array}{l}\text { Kerato conjunctivitis, } \\
\text { photophobia }\end{array}$ & & \\
\hline
\end{tabular}

coinfected individuals in Madrid, Navas et al. [35] found paradoxical worsening in six (35\%) after initiation of HAART. Initiation of HAART shortly after starting MTB therapy and larger decrement in HIV-1 viral load were associated with development of paradoxical reactions. Breen et al. [36••] described paradoxical reactions to MTB after starting HAART in eight of 28 (29\%) HIV-1-infected patients coinfected with MTB in London. Paradoxical reactions were significantly associated with starting HAART within 6 weeks of MTB diagnosis [36・•] and with disseminated disease at baseline [36••,37]. In each of these trials, control groups consisting of HIV-1 seropositive individuals who were not receiving antiretroviral therapy, and/or HIV1 seronegative patients with MTB, had incidences of paradoxical reactions to MTB of $0 \%$ to $10 \%$.
Most (92\%) of 57 cases $[4,14,24,26,34,35,36 \bullet \cdot, 37-47]$ of MTB IRS described in the literature presented as recurrent or worsening disease, whereas some $(8 \%)$ were newly diagnosed MTB. Fever (50\%), new or worsening lymphadenopathy (37\%), and worsening pulmonary symptoms and/or infiltrates (33\%) were the most common presenting signs or symptoms. Other findings included weight loss, acute respiratory distress syndrome, hypercal cemia, and worsening symptoms from extrapulmonary disease (eg, CNS lesions, abdominal pain, pleural effusions, ascites, hepatosplenomegaly, scrotal swelling, or cutaneous lesions). Median nadir CD4+T-cell counts were 36 ( range $=2-220$ ) cell $\mathrm{s} / \mathrm{mm}^{3}$. Increased CD4+T-cell counts occurred in many, but not all, patients with MTB IRS. Except in the few cases of primary MTB IRS $[4,26,39,40]$, all patients 
were on multidrug antituberculosis regimens at the time of clinical worsening.

The median time to presentation with a paradoxical reaction to MTB after initiation of HAART was 15 days. Diagnosis was generally clinical. When biopsies were performed, three of seven were AFB stain-positive, and four of eight were culture-positive [4,24,39-41,46]. Four separate cases reported granul omata on histology $[4,24,40]$. Management usually consisted of continuation of antiretroviral therapy and antituberculosis chemotherapy. Steroids were used in one third of cases, usually in severely affected patients. No mortality or significant residual morbidity were reported.

Currently, it is recommended that HAART be started at least 2 months after initiation of antituberculosis chemotherapy to minimize drug interactions and to reduce the incidence of MTB IRS [33]. Nevertheless, delaying initiation of HAART will not completely prevent the occurrence of MTB IRS. In the cases reviewed, 36\% occurred in patients who initiated HAART 60 or more days after starting antituberculosis therapy. Prospective, randomized trials are needed to identify the individuals most at risk for MTB IRS and the optimal time to initiate HAART.

\section{Cryptococcus neoformans}

Cryptococcal IRS have been reported frequently, although estimates of their incidence are quite disparate Two small retrospective studies estimated the incidence of cryptococcal IRS at 50\% $(n=10)$ and $60 \%(n=5)$ in patients with a history of cryptococcal disease $[48,49]$. However, in a much larger prospective study in Thailand, cryptococcal disease recurred in only $5 \%$ of 60 patients who were recei ving prophylaxis for cryptococcal disease and who initiated HAART [14]. The reasons for these discrepant estimates are unclear but could be attributed to selection bias introduced by retrospective studies.

Of 32 cases of cryptococcal IRS reported in theliterature [4,28,48-59], most (84\%) occurred in individuals with a prior history of cryptococcal disease Presentations of cases of cryptococcal IRS included fever (52\%), Iymphadenitis (44\%), meningitis (40\%), pulmonary disease (13\%), cere bral cryptococcomas ( $9 \%$ ), cutaneous disease (3\%), or hypercal cemia (3\%). Median nadir CD4+T-cell counts were $29 \mathrm{cells} / \mathrm{mm}^{3}$, and on presentation with IRS, the median CD4+T-cell count was 175 cells $/ \mathrm{mm}^{3}$. In cases of recurrent cryptococcal illness, the median time from diagnosis of primary cryptococcal disease to initiation of HAART was 21 days, and the median time to presentation with cryptococcal IRS was 120 days later. Individuals with primary cryptococcal IRS presented earlier after starting HAART (median = 30 days) than did those with recurrent cryptococcal disease

Diagnosis of cryptococcal IRS was usually based on clinical grounds, specifically the new onset of cryptococcal disease or worsening of symptoms in individuals who had previously responded to cryptococcal treatment. To date, no studies have evaluated whether cryptococcalspecific immunity is enhanced during HAART therapy. Histology of excised Iymph nodes has universally shown yeast consistent with Cryptococcus; however, none of 11 culture results was positive. Treatment outcomes were good with continuation of HAART in the presence ( $n=12$ ) or absence ( $n=7$ ) of antifungal therapy. Several patients received steroids $[4,54,58]$ or nonsteroidal antiinflammatory drugs [54,55].

\section{Pneumocystis jirovecii}

Two retrospective studies estimated the incidence of Pneumocystis jirovecii pneumonia (PCP) IRS in patients with a history of PCP at $4.6 \%(n=65)$ and $18.8 \%(n=16)$ $[60,61]$. Despite these high estimates, few cases of PCP IRS have been reported. Of 15 cases of PCP IRS reported in the literature and reviewed here [4,28,60-63], 11 (73\%) occurred in individuals with a prior diagnosis of PCP. Symptoms and signs of PCP IRS were typical for PCP pneumonia, including respi ratory complaints, fever, and pneumonia. Atypical presentations or findings were not noted. Ten of 11 cases of recurrent disease presented within 17 days of starting HAART. Nadir CD4+T-cell counts were less than $100 \mathrm{cells} / \mathrm{mm}^{3}$ in $78 \%$ of patients, and follow-up counts were not significantly changed. PCP organisms were detected in five of six bronchoalveolar lavage and/or transbronchial biopsy specimens [4,60,61,63]. Although enhanced PCP-specific cellular immune responses have been reported in HAART-treated patients [64], such studies have not been performed in cases of PCP IRS.

The importance of attenuating the immune response in PCP was recognized even in the pre-HAART era when steroid therapy was recommended in severe cases [65]. In virtually all of the cases of recurrent PCP IRS reviewed in the literature, patients had received inadequate steroid therapy for the primary infection, or HAART had been initiated before completion of a 3-week course of therapy for PCP [60-63]. In most cases of PCP IRS, PCP-specific therapy was continued or changed, and steroids were used when symptoms were severe HAART was temporarily discontinued in at least two patients with refractory symptoms [61]. Despite the severity of symptoms, all patients recovered.

\section{Cytomegal ovirus}

Inflammatory reactions to CMV have been one of the most frequently reported IRS events in the HAART era. The incidence of newly diagnosed (primary) CMV disease after initiating HAART has been found to be approximately $5 \%$ in patients with Iow CD4+T-cell nadirs [66,67]. In individuals with a prior diagnosis of CMV disease, two retrospective studies suggested that CMV IRS occurs in $4.6 \%$ to $7.3 \%$ of patients $[68,69]$, whereas two prospective 
studies found CMV IRS in $41 \%$ to $63 \%[70,71]$ of patients. It is possible that the prospective studies were more sensitive to subtle symptoms and signs of CMV IRS than were the retrospective studies.

We reviewed 110 cases of CMV IRS reported in the literature [4,25,28,59,66,67,69-81]. Patients with ocular CMV IRS usually presented with a decrease in vision and visually significant floaters in the affected eye(s) [75]. Examination findings showed inflammatory changes not typically seen in pre-HAART CMV retinitis, specifically immune vitreitis or immune uveitis. Cases of nonocular CMV IRS included pneumonitis [4,79], pancreatitis [67], gastrointestinal disease [28,67], parotitis [4], Iymphadenitis [67], and neurological disease [28]. Nadir CD4+T-cell counts were uniformly less than $100 \mathrm{cell} / \mathrm{s} / \mathrm{mm}^{3}$ in reported cases of CMV IRS. At thetime of presentation, median CD4+ T-cell counts were 119 (range $=5-780$ ) cell s $/ \mathrm{mm}^{3}$ [25]. Patients with recurrent disease had usual ly been on active or suppressive anti-CMV therapies at the time of recurrence. The time to presentation with symptoms after HAART did not differ significantly between primary CMV IRS ( median $=50$ days) and recurrent CMV IRS (median $=60$ days). Primary CMV IRS has been associated with detectable CMV viremia at the time that HAART was started [66], but the utility of assaying for CMV viremia in recurrent CMV IRS has not been studied. Restoration of CMV-spedific CD4+ T-cell responses has been demonstrated in individuals during HAART treatment [12], but such studies have not been performed in individuals with CMV IRS

All patients with CMV IRS were maintained on HAART. Specific anti-CMV therapy was used in approximately $50 \%$ of reported cases, particularly in those with primary CMV IRS. Topical, intravitreal, and systemic corticosteroids were used in approximately one third of cases, with good outcomes. In most cases, disease progression was halted with these measures. However, significant ocular morbidity including blindness or permanent visual deficits have been reported in some patients $[68,75,76,80]$.

\section{JC Virus}

Progressive multifocal leukoencephalopathy (PML) is a demyelinating disease of the CNS that is caused by the polyomavirus JC virus (JCV) and occurs in advanced HIV-1 infeCtion. HAART is the primary treatment for PML, but has been associated with new-onset or worsening clinical disease in some cases [82-90]. Of 26 cases of PML IRS in the English literature that were reviewed, 16 were new diagnoses and 10 represented progression of known disease The symptoms at presentation were typical of PML, including focal neurologic findings, visual changes, coordination difficulties, dysarthria, dysphagia, cognitive problems, and seizures. Median nadir CD4+T-cell counts were $39 \mathrm{cells} / \mathrm{mm}^{3}$, and CD4+T cells had increased to a median of $149 \mathrm{cell} / \mathrm{s} / \mathrm{mm}^{3}$ at presentation. Median time to presentation with symptoms after starting HAART was 49 days.
To date, no studies of the impact of HAART on JCVspecific immunity have been performed. Most cases of PML IRS have been diagnosed by magnetic resonance imaging (MRI) changes with or without biopsy and/or cerebrospinal fluid polymerase chain reaction analysis for JCV. The primary difference between PML IRS and classic PML has been the presence of inflammation, which was rarely seen in the pre-HAART era. Contrast enhancement on MRI was found in four of six patients with MRI data available $[82,84,85]$. Biopsy results were reported in eight cases, and perivascular inflammatory infiltrates were seen in seven of these $[83,84,88-90]$. In one study of five PML patients who initiated HAART and who had follow-up MRI scanning, all demonstrated worsening findings by MRI, yet only two had a worsening clinical course[86]. Prognosis of AIDS patients with PML has improved with HAART, but it remains poor [91]. In the IRS cases reviewed, more than one third of patients died and most who survived had significant persistent neurological deficits.

\section{Hepatitis B Virus and Hepatitis C Virus}

Hepatic enzyme abnormalities are frequently observed in individuals on HAART. Their etiology is multifactorial, including antiretroviral or other prescription drug toxicity, al cohol or recreational drug use, hepatitis caused by other infectious etiologies, and nonal coholic steatohepatitis (NASH). Multiple studies have shown that HIV-1-infected individuals with chronic hepatitis B virus (HBV) and/or HCV infections are at particular risk for developing severe hepatic enzyme el evations and liver damage after starting HAART [92-95], and it has been suggested that at least some of these may be IRS.

Flares of hepatitis B have been reported in several patients after the initiation of HAART and attributed to IRS [96-101]. In some cases, hepatic enzyme abnormal ities eventually resolved in association with seroconversion and clearance of HBsAg, HBeAg, and/or HBV DNA [96-98]. In others, hepatic enzyme abnormalities resolved with discontinuation of antiretroviral therapy $[98,99]$, or worsened, resulting in death [99]. Liver biopsies in many of these patients reveal ed findings consistent with viral hepatitis, rather than drug toxicity.

Flares of hepatitis C in HIV-1-infected individuals after initiation of HAART have al so been reported as IRS. Two cases of previously undiagnosed HCV infections have been discovered secondary to transaminase flares and new seroconversion to HCV after starting HAART [102]. Other complications in HCV-infected patients after starting antiretroviral therapy that have been reported as IRS include cirrhosis, hepatic failure, and porphyria cutanea tarda $[102,103]$. Liver biopsies in 16 HIV-1- and HCV-coinfected individuals in whom severe hepatotoxicity occurred after initiation of HAART demonstrated findings consistent with viral hepatitis [95], supporting the diagnosis of IRS. 
No studies to date have assessed the impact of HAART on viral hepatitis-specific cellular immune responses and their relationship to hepatic enzyme el evations. Because diagnosis of HBV or HCV IRS can never be certain, manage ment of these cases is similar to that for any HIV-1-infected patient with liver function test abnormalities [104]. Antiretroviral therapy and potentially hepatotoxic drugs must be stopped if liver function test abnormalities are severe, and other causes of liver function abnormalities must be excluded through testing. It has been recommended that patients with HBV and HIV-1 coinfection be treated with lamivudine and tenofovir-containing HAART regimens to prevent flares of HBV replication [100]. In addition, a nonrandomized study reported that treatment of HCV with interferon- $\alpha$ or interferon- $\alpha$ with ribavirin before HAART decreased the incidence of severe liver toxicity in these individuals [105]. Prospective randomized trials are critical to determine the optimal timing of therapy for chronic viral hepatitis and HIV-1 in coinfected individuals.

\section{Varicella Zoster Virus}

A two- to fivefold increased incidence of zoster after initiation of antiretroviral therapy has been reported, compared with historical controls [106,107]. Most patients with reported varicella zoster virus (VZV) IRS present before 16 weeks of HAART and most commonly with dermatomal zoster [106-108]. Ocular disease $[4,28,109]$ and transverse myelitis [110] have been reported as VZV IRS events as well. Nadir CD4+T-cell counts have been less than $200 \mathrm{cell} / \mathrm{s} / \mathrm{mm}^{3}$ with modest increases of 40 to 60 cells $/ \mathrm{mm}^{3}$ at the time of presentation. Zoster was the only IRS reported in a study of 61 children who received HAART for at least 6 months; seven (11.5\%) of these children developed cutaneous zoster [111]. CD4+ T-cell nadirs were significantly lower in children who developed zoster ( mean $=191 \mathrm{cell} / \mathrm{s} / \mathrm{mm}^{3}$ ), compared with children who did not ( mean $=769 \mathrm{cells} / \mathrm{mm}^{3}$ ). The risk of developing zoster was associated with lack of protective levels of varicella-specific immunoglobulin $\mathrm{G}$ in patients with a previous history of VZV infection. Children were treated with intravenous acyclovir and continuation of HAART with rapid resolution in all instances. Steroids were used in a case of transverse myelitis [110], but were not used in other VZV IRS.

\section{Human Papilloma Virus}

Increases in the incidence and prevalence of oral warts caused by human papilloma virus (HPV) have been observed in HIV-1-infected individuals during the HAART era. Greenspan et al. [112] reported that oral warts were six times more common in patients on HAART than in patients on no antiretroviral therapy. Subsequently, King et al. [113] showed a prevalence of oral warts in an inner city HIV oral heal th clinic to be $2.6 \%$ in the HAART era. Multivariate analysis showed an association between oral warts and a 1log or more decrease in HIV-1 RNA in the 6 months before diagnosis of oral warts, suggesting a possible rel ationship between oral warts and immune reconstitution. Surgical and medical modalities of treatment are used in treatment of oral warts, but management is chal lenging because warts often recur [114]. The impact of HAART on cervical and anal HPV infections remains controversial [115], but no cases of IRS to anal or genital HPV infections have been reported.

\section{Kaposi 's Sarcoma}

Highly active antiretroviral therapy results in complete or partial resolution of Kaposi's sarcoma (KS) lesions in $55 \%$ to $60 \%$ of AIDS-KS patients [116,117]. Nevertheless, five cases of KS IRS have been reported after initiation of HAART $[4,118-120]$. Three cases manifested as worsening $\mathrm{KS}$, and two were new diagnoses. Nadir CD4+T-cell counts were less than $100 \mathrm{cells} / \mathrm{mm}^{3}$ in four of the five cases, and virologic responses to HAART occurred in all instances. Acute worsening of previously diagnosed KS resulting in facial edema and cervical lymphadenopathy in one case [119] and epiglottal swelling and threatened laryngeal obstruction in the second [118] occurred 10 days and 8 weeks after starting HAART, respectively. New KS was diagnosed on the skin 5 months after starting HAART [4] and in the parotid 2 years after initiation of HAART [120].

Diagnosis of KSIRS was based on clinical presentations primarily. In one case, KS-associated herpesvirus DNA was shown to decline coincident with the clinical KS flare, supporting the diagnosis of KS IRS rather than progressive KS [119]. Treatment modalities and outcomes were reported for three of the KS IRS events, and in all three cases, HAART was continued. Radiotherapy, surgical excision, and chemotherapy were used with good outcomes in all instances.

\section{Pathogenesis of Immune \\ Reconstitution Syndrome}

Highly active antiretroviral therapy restores CD4+T-cell numbers and the ability of the immune system to respond to antigens. Enhanced lymphocyte proliferative responses and DTH responses to opportunistic pathogens, including CMV, Candida, Pneumocystis ji rovecii, MTB, and MAC, have been demonstrated in multiple studies [11-13,19,64] and strongly support the notion that reconstitution of pathogenspecific cellular immunity results in IRS. Maximal recovery of these responses is quite rapid, usual ly within the first 12 weeks of therapy [13], and is consistent with the reported rapid onset of symptoms of IRS in many cases after initiation of HAART. It is unclear whether cases of IRS with a late onset (ie, after 12 weeks) involve the same pathogenic mechanisms as IRS that occur within the first 3 months [8]. Late-onset IRS could represent delayed cellular immune 
reconstitution and/or a lower antigen load. Alternatively, they may reflect some distinct process such as an autoimmuneor hypersensitivity reaction.

The nature of the immune restoration that occurs in IRS is controversial. French et al. [7] have postulated that atypical presentations of opportunistic infections during HAART are caused by restoration of an immunopathologic response, rather than an immunoprotective response. They hypothesize that IRS represents a dysregulation of the immune response to a specific pathogen, and that individuals with low CD4+T-cell nadirs are more vulnerable to these responses because they have a greater susceptibility to immune dysregulation during immune reconstitution. An alternative explanation that is favored by the present authors is that IRS represents the vigorous reconstitution of normal immune responses to an unusually large antigen Ioad. The association of IRS with low CD4+T-cell nadirs supports the notion that large amounts of antigen may have been allowed to accumulate in the absence of adequate immune surveillance. Differences in antigen load could explain why one patient develops IRS and another does not. The fact that cellular immune responses (when they have been measured during IRS) $[12,19]$ are similar to those in individual snot experiencing IRS, but undergoing immune reconstitution to HAART, further supports the notion that the immune response is normal. Other variables, such as the host's ability to reconstitute immunity, may also play a role in addition to antigen load. Further studies are needed to better characterize the types of immune responses that occur in IRS and to determine the contributions of antigen load and immune response to IRS.

Immune reconstitution syndrome to human herpes viruses has been associated with specific major histocompatibility complex (MHC) haplotypes and cytokine gene polymorphisms, whereas different MHC haplotypes and cytokine gene polymorphisms were reportedly associated with MAC IRS [121,122]. These data suggest that there may be a genetic susceptibility to IRS. However, the numbers of individuals with IRS included in these studies were small, and further studies are needed to confirm these observations. Individuals with herpesvirus IRS have been reported to have increased plasma interleukin- 6 levels before HAART, and these levels increase over time on HAART [123]. An increase in CD8+T cells correl ated with the occurrence of zoster after HAART in one study [106], and CD8+T cells have al so been hypothesized to bethe cause of IRS hepatitis assodiated with HBV and HCV $[97,102,124]$. Whether increased levels of interleukin-6 or CD8+T cells precipitated IRS in these cases or the diseases themsel ves precipitated the increased interleukin- 6 levels and CD8+T-cell counts remains to be determined.

\section{Conclusions}

A variety of IRS have been described since the introduction of HAART, ranging in severity from relatively minor clinical events, such as zoster, to severe and life-threatening diseases, including worsening MTB and hepatitis. Strong evidence of IRS is present in some instances, including MAC and MTB. However, evidence to support the diagnosis of IRS is only suggestive in cases of CMV and PML, and distinctly lacking in other reported IRS such as chronic HBV and HCV. Knowledge of the presentation and management of IRS is largely anecdotal. Prospective studies are critical to better define the incidence, predictors, and pathogenesis of IRS. Randomized controlled trials areal so necessary, particularly in HIV-1-infected individual s coinfected with MTB or hepatitis C, to develop strategies to decrease the incidence of IRS and to define their appropriate management.

As HAART is progressively introduced into resourcelimited settings, where thresholds for initiating therapy are often less than $200 \mathrm{CD} 4+\mathrm{T}$ cell $\mathrm{s} / \mathrm{mm}^{3}$, it is likely that IRS will be observed more frequently. With the advent of HAART in Africa, MTB and KS IRS are likely to increase substantially because of the high level s of latent MTB and human herpesvirus-8 infection in the population. Furthermore, it is anticipated that other forms of IRS that have not yet been described may be seen as HAART is introduced into different regions of the world. Indeed, uveitis has been attributed to IRS to Leishmania major in an HIV-1-infected man from Burkina Faso [125], and borderline tuberculoid leprosy with a reversal reaction has been ascribed to IRS to M ycobacterium leprae in an HIV-1infected man from Uganda [126]. As antiretroviral therapy is introduced into different regions, it is critical that prospective clinical studies be performed to define the spectrum, incidence, and predictors of IRS and the optimal management of these syndromes in each specific geographic setting, because they may differ. A better understanding of IRS is critical to optimal management of antiretroviral treatment of HIV-1-infected individuals in the 21st century.

\section{References and Recommended Reading}

Papers of particular interest, published recently, have been

highlighted as:

- Of importance

-. Of major importance

1. Palella FJ Jr, Delaney KM, Moorman AC, et al.: Declining morbidity and mortality among patients with advanced human immunodeficiency virus infection. HIV Outpatient Study Investigators. N Engl J M ed 1998, 338:853-860.

2. Hirsch HH, Kaufmann G, Sendi P, Battegay M: Immune reconstitution in HIV-infected patients. Clin Infect D is 2004, 38:1159-1166.

3. • French MA, Lenzo N, John M, et al.: Immune restoration disease after the treatment of immunodeficient HIV-infected patients with highly active antiretroviral therapy. HIV M ed 2000, 1:107-115.

This paper estimates the incidence of IRS to be $25 \%$ in HAART responders. It contains a detailed discussion of each event and correlates events with pathogen-specific immune responses. 
4. Shelburne SA 3rd, Hamill RJ, Rodriguez-Barradas MC, et al.: Immune reconstitution inflammatory syndrome: emergence of a unique syndrome during highly active antiretroviral therapy. M edicine (Baltimore) 2002, 81:213-227.

5. Cheng VC, Yuen KY, Chan WM, et al.: Immunorestitution disease involving the innate and adaptive response. Clin Infect D is 2000, 30:882-892.

6. French MA, Mallal SA, Dawkins RL: Zidovudine-induced restoration of cell-mediated immunity to mycobacteria in immunodeficient HIV-infected patients. AIDS 1992, 6:1293-1297.

7. French MA, Price P, Stone SF: Immune restoration disease after antiretroviral therapy. AIDS 2004, 18:1615-1627.

8. Cooney EL: Clinical indicators of immune restoration following highly active antiretroviral therapy. Clin Infect D is 2002, 34:224-233.

9. Shelburne SA 3rd, Hamill RJ: The immune reconstitution inflammatory syndrome. AID S Rev 2003, 5:67-79.

10. DeSimoneJA, Pomerantz RJ, Babinchak TJ: Inflammatory reactions in HIV-1-infected persons after initiation of highly active antiretroviral therapy. Ann Intern M ed 2000, 133:447-454.

11. Autran B, Carcelaint G, Li TS, et al.: Restoration of the immune system with anti-retroviral therapy. Immunol Lett 1999, 66:207-211.

12. Komanduri KV, Viswanathan MN, Wieder ED, et al.: Restoration of cytomegalovirus-specific CD 4+ T-lymphocyte responses after ganciclovir and highly active antiretroviral therapy in individuals infected with HIV-1. $N$ at M ed 1998, 4:953-956.

13. Connick E, Lederman MM, Kotzin BL, et al.: Immune reconstitution in the first year of potent antiretroviral therapy and its relationship to virologic response. I Infect D is 2000, 181:358-363.

14. Sungkanuparph S, Vibhagool A, Mootsikapun P, et al.: O pportunistic infections after the initiation of highly active antiretroviral therapy in advanced AIDS patients in an area with a high prevalence of tuberculosis. AIDS 2003, 17:2129-2131.

15. Race EM, Adelson-MittyJ, Kriegel GR, et al.: Focal mycobacterial lymphadenitis following initiation of protease-inhibitor therapy in patients with advanced HIV-1 disease. Lancet 1998, 351:252-255.

16. Di Perri G, BonoraS, Vento $S$, et al.: Highly active antiretroviral therapy. Lancet 1998, 351:1056; author reply 1058-1059.

17. Dworkin MS, Fratkin MD: Mycobacterium avium complex lymph node abscess after use of highly active antiretroviral therapy in a patient with AIDS. Arch Intern M ed 1998, 158:1828.

18. CabieA, Abel S, Brebion A, et al.: Mycobacterial lymphadenitis after initiation of highly active antiretroviral therapy. Eur J Clin M icrobiol Infect D is 1998, 17:812-813.

19. Foudraine NA, Hovenkamp E, Notermans DW, et al.: Immunopathology as a result of highly active antiretroviral therapy in HIV-1-infected patients. AIDS 1999, 13:177-184.

20. Phillips P, Kwiatkowski MB, Copland M, et al.: Mycobacterial lymphadenitis associated with the initiation of combination antiretroviral therapy. J Acquir I mmune D efic Syndr H um Retrovirol 1999, 20:122-128.

21. del Giudice P, Durant J, Counillon E, et al.: Mycobacterial cutaneous manifestations: a new sign of immune restoration syndrome in patients with acquired immunodeficiency syndrome. Arch Dermatol 1999, 135:1129-1130.

22. Price $L M, O$ 'Mahony $C$ : Focal adenitis developing after immune reconstitution with HAART. Int J STD AID S 2000, 11:685-686.

23. AbergJA, Chin-Hong PV, McCutchan A, et al.: Localized osteomyelitis due to Mycobacterium avium complex in patients with human immunodeficiency virus receiving highly active antiretroviral therapy. Clin Infect D is 2002, 35:E8-E13.

24. Buckingham SJ, Haddow LJ, Shaw PJ, Miller RF: Immune reconstitution inflammatory syndrome in HIV-infected patients with mycobacterial infections starting highly active anti-retroviral therapy. Clin Radiol 2004, 59:505-513.
25. Behrens GM, Meyer D, Stoll M, Schmidt RE: Immune reconstitution syndromes in human immunodeficiency virus infection following effective antiretroviral therapy. Immunobiology 2000, 202:186-193.

26. PowlesT, Thirlwell C, Nelson M, Bower M: Immune reconstitution inflammatory syndrome mimicking relapse of AID S related lymphoma in patients with HIV 1 infection. Leuk Lymphoma 2003, 44:1417-1419.

27. Lawn SD, Bicanic TA, Macallan DC: Pyomyositis and cutaneous abscesses due to Mycobacterium avium: an immune reconstitution manifestation in a patient with AIDS. Clin Infect D is 2004, 38:461-463.

28. Michelet C, ArvieuxC, Francois C, et al.: O pportunistic infections occurring during highly active antiretroviral treatment. AIDS 1998, 12:1815-1822.

29. Cinti SK, Kaul DR, Sax PE, et al.: Recurrence of Mycobacterium avium infection in patients receiving highly active antiretroviral therapy and antimycobacterial agents. Clin Infect D is 2000, 30:511-514.

30. Brown M, Williams IG, Miller RF: Deterioration of disseminated cutaneous Mycobacterium avium complex infection with a leukaemoid reaction following institution of highly active antiretroviral therapy. Sex Transm Infect 2001, 77:149-150.

31. Murray R, Mallal S, Heath C, French M: Cerebral mycobacterium avium infection in an HIV-infected patient following immune reconstitution and cessation of therapy for disseminated mycobacterium avium complex infection. Eur J Clin M icrobiol Infect Dis 2001, 20:199-201.

32. Cheng VC, Yam WC, Woo PC, et al.: Risk factors for development of paradoxical response during antituberculosis therapy in HIV-negative patients. Eur J Clin M icrobiol Infect D is 2003, 22:597-602.

33. Burman WJ, Jones BE: Treatment of HIV-related tuberculosis in the era of effective antiretroviral therapy. Am J Respir Crit Care M ed 2001, 164:7-12.

34. Narita M, Ashkin D, Hollender ES, Pitchenik AE: Paradoxical worsening of tuberculosis following antiretroviral therapy in patients with AIDS. Am J Respir Crit Care M ed 1998, 158:157-161.

35. Navas E, Martin-Davila P, Moreno L, et al.: Paradoxical reactions of tuberculosis in patients with the acquired immunodeficiency syndrome who are treated with highly active antiretroviral therapy. Arch Intern M ed 2002, 162:97-99.

36. • Breen RA, Smith CJ, Bettinson $\mathrm{H}$, et al.: Paradoxical reactions during tuberculosis treatment in patients with and without HIV co-infection. Thorax 2004, 59:704-707.

This study determined the frequency of MTB IRS to be $29 \%$ in patients with known HIV-MTB coinfection. The authors correlated it with earlier initiation of HAART after MTB diagnosis.

37. Wendel KA, Alwood KS, Gachuhi R, et al.: Paradoxical worsening of tuberculosis in HIV-infected persons. Chest 2001, 120:193-197.

38. Orlovic D, Smego RA Jr: Paradoxical tuberculous reactions in HIV-infected patients. Int J Tuberc Lung D is 2001, 5:370-375.

39. Goldsack NR, Allen S, Lipman MC: Adult respiratory distress syndrome as a severe immune reconstitution disease following the commencement of highly active antiretroviral therapy. Sex Transm Infect 2003, 79:337-338.

40. Crump JA, Tyrer MJ, Lloyd-Owen SJ, et al.: Military tuberculosis with paradoxical expansion of intracranial tuberculomas complicating human immunodeficiency virus infection in a patient receiving highly active antiretroviral therapy. Clin Infect D is 1998, 26:1008-1009.

41. Guex AC, Bucher HC, Demartines N, et al.: Inflammatory bowel perforation during immune restoration after one year of antiretroviral and antituberculous therapy in an HIV-1-infected patient: report of a case. D is Colon Rectum 2002, 45:977-978.

42. John M, French MA: Exacerbation of the inflammatory response to Mycobacterium tuberculosis after antiretroviral therapy. M ed J Aust 1998, 169:473-474. 
43. Chien JW, Johnson JL: Paradoxical reactions in HIV and pulmonary TB. Chest 1998, 114:933-936.

44. Furrer $\mathrm{H}$, Malinverni R: Systemic inflammatory reaction after starting highly active antiretroviral therapy in AIDS patients treated for extrapulmonary tuberculosis. Am J M ed 1999, 106:371-372.

45. Fishman JE, Saraf-Lavi E, Narita M, et al.: Pulmonary tuberculosis in AIDS patients: transient chest radiographic worsening after initiation of antiretroviral therapy. AJR Am J Roentgenol 2000, 174:43-49.

46. Lawn SD, Macallan DC: Hypercalcemia: a manifestation of immune reconstitution complicating tuberculosis in an HIVinfected person. Clin Infect D is 2004, 38:154- 155.

47. Hollender ES, Narita M, Ashkin D, et al.: CNS manifestations of paradoxical reaction in HIV+ TB patients on HAART. Paper presented at the 7th Conference on Retroviruses and 0 pportunistic Infections. San Francisco, CA; January 30-February 2, 2000.

48. Trevenzoli M, Cattelan AM, Rea F, et al.: Mediastinitis due to cryptococcal infection: a new clinical entity in the HAART era. J Infect 2002, 45:173-179.

49. Jenny-Avital ER, Abadi M: Immune reconstitution cryptococcosis after initiation of successful highly active antiretroviral therapy. Clin Infect D is 2002, 35:e128-e133.

50. Cattelan AM, Trevenzoli M, Sasset L, et al.: Multiple cerebral cryptococcomas associated with immune reconstitution in HIV-1 infection. AIDS 2004, 18:349-351.

51. Cinti SK, Armstrong WS, Kauffman CA: Case report. Recurrence of increased intracranial pressure with antiretroviral therapy in an AIDS patient with cryptococcal meningitis. M ycoses 2001, 44:497-501.

52. Lanzafame M, Trevenzoli M, Carretta G, et al.: Mediastinal lymphadenitis due to cryptococcal infection in HIV-positive patients on highly active antiretroviral therapy. Chest 1999, 116:848-849.

53. Woods ML 2nd, MacGinley R, Eisen DP, Allworth AM: HIV combination therapy: partial immune restitution unmasking latent cryptococcal infection. AIDS 1998, 12:1491-1494.

54. Blanche P, Gombert B, Ginsburg C, et al.: HIV combination therapy: immune restitution causing cryptococcal lymphadenitis dramatically improved by anti-inflammatory therapy. Scand J Infect Dis 1998, 30:615-616.

55. Manfredi R, Pieri F, Pileri SA, Chiodo F: The changing face of AID S-related opportunism: cryptococcosis in the highly active antiretroviral therapy (HAART) era. Case reports and literature review. M ycopathologia 1999, 148:73-78.

56. Rambeloarisoa J, Batisse D, Thiebaut JB, et al.: Intramedullary abscess resulting from disseminated cryptococcosis despite immune restoration in a patient with AIDS. J Infect 2002, 44:185-188.

57. Breton $G$, Seilhean $D$, Cherin $P$, et al.: Paradoxical intracranial cryptococcoma in a human immunodeficiency virus-infected man being treated with combination antiretroviral therapy. Am J M ed 2002, 113:155-157.

58. King MD, Perlino CA, Cinnamon J, Jernigan JA: Paradoxical recurrent meningitis following therapy of cryptococcal meningitis: an immune reconstitution syndrome after initiation of highly active antiretroviral therapy. Int J STD AIDS 2002, 13:724-726.

59. Legendre U, Battegay M, Nuttli I, et al.: Simultaneous occurrence of 2 HIV-related immunereconstitution diseases after initiation of highly active antiretroviral therapy. Scand J Infect $D$ is 2001, 33:388-389.

60. Dean GL, Williams DI, Churchill DR, Fisher MJ: Transient clinical deterioration in HIV patients with Pneumocystis carinii pneumonia after starting highly active antiretroviral therapy: another case of immune restoration inflammatory syndrome. Am J Respir Crit Care M ed 2002, 165:1670; author reply 1670.

61. Wislez $M$, Bergot $E$, Antoine $M$, et al.: Acute respiratory failure following HAART introduction in patients treated for Pneumocystis carinii pneumonia. Am J Respir Crit Care M ed 2001, 164:847-851.
62. Lim L, Street AC, Lewin SR: Pneumocystis carinii pneumonia after cessation of secondary prophylaxis in a patient on highly active antiretroviral therapy with a CD4 cell count greater than 200/mm3. AIDS 2001, 15:1912-1913.

63. Koval CE, Gigliotti F, Nevins D, Demeter LM: Immune reconstitution syndrome after successful treatment of Pneumocystis carinii pneumonia in a man with human immunodeficiency virus type 1 infection. Clin Infect D is 2002, 35:491-493.

64. Atzori C, Clerici M, Trabattoni D, et al.: Assessment of immune reconstitution to Pneumocystis carinii in HIV-1 patients under different highly active antiretroviral therapy regimens. J Antimicrob Chemother 2003, 52:276-281.

65. BozzetteSA, Sattler FR, Chiu J, et al.: A controlled trial of early adjunctive treatment with corticosteroids for Pneumocystis carinii pneumonia in the acquired immunodeficiency syndrome. California Collaborative Treatment Group. N Engl J M ed 1990, 323:1451-1457.

66. Casado JL, Arrizabalaga J, Montes M, et al.: Incidence and risk factors for developing cytomegalovirus retinitis in HIV-infected patients receiving protease inhibitor therapy. Spanish CMVAIDS Study Group. AID S 1999, 13:1497-1502.

67. Gilquin J, Piketty C, Thomas V, et al.: Acute cytomegalovirus infection in AIDS patients with CD4 counts above $100 x$ 10(6) cells/l following combination antiretroviral therapy including protease inhibitors. AID S 1997, 11:1659-1660.

68. Nguyen QD, Kempen JH, Bolton SG, et al.: Immune recovery uveitis in patients with AIDS and cytomegalovirus retinitis after highly active antiretroviral therapy. Am J 0 phthalmol 2000, 129:634-639.

69. Karavellas MP, Lowder CY, Macdonald C, et al.: Immune recovery vitritis associated with inactive cytomegalovirus retinitis: a new syndrome. Arch O phthalmol 1998, 116:169-175.

70. Jouan M, Saves M, Tubiana R, et al.: Discontinuation of maintenance therapy for cytomegalovirus retinitis in HIV-infected patients receiving highly active antiretroviral therapy. AIDS 2001, 15:23-31.

71. Karavellas MP, Plummer DJ, Macdonald JC, et al.: Incidence of immune recovery vitritis in cytomegalovirus retinitis patients following institution of successful highly active antiretroviral therapy. J Infect D is 1999, 179:697-700.

72. Deayton JR, Wilson P, Sabin CA, et al.: Changes in the natural history of cytomegalovirus retinitis following the introduction of highly active antiretroviral therapy. AID S 2000, 14:1163-1170.

73. Nguyen QD, Kempen JH, Bolton SG, et al.: Immune recovery uveitis in patients with AIDS and cytomegalovirus retinitis after highly active antiretroviral therapy. Am J 0 phthalmol 2000, 129:634-639.

74. Stone SF, PriceP, Tay-Kearney ML, French MA: Cytomegalovirus (CMV) retinitis immune restoration disease occurs during highly active antiretroviral therapy-induced restoration of CMV-specific immune responses within a predominant Th2 cytokine environment. J Infect D is 2002, 185:1813-1817.

75. Karavellas MP, Song M, Macdonald JC, Freeman WR: Long-term posterior and anterior segment complications of immune recovery uveitis associated with cytomegalovirus retinitis. Am J O phthalmol 2000, 130:57-64.

76. Zegans ME, Walton RC, Holland GN, et al.: Transient vitreous inflammatory reactions associated with combination antiretroviral therapy in patients with AIDS and cytomegalovirus retinitis. Am J O phthalmol 1998, 125:292-300.

77. Sanislo SR, Lowder CY, Kaiser PK: O ptic nerve head neovascularization in a patient with inactive cytomegalovirus retinitis and immune recovery. Am J O phthalmol 1998, 126:318-320.

78. Boyraz-Ikiz HD, Witmer JP, Frissen PH: Cytomegalovirus (re)activation plays no role in the ocular vitritis observed after initiation of highly active antiretroviral therapy. AIDS 1999, 13:867.

79. Miller RF, Shaw PJ, Williams IG: Immune reconstitution CMV pneumonitis. Sex Transm Infect 2000, 76:60.

80. Whitcup SM: Cytomegalovirus retinitis in the era of highly active antiretroviral therapy. JAM A 2000, 283:653-657. 
81. Jacobson MA, Zegans M, Pavan PR, et al.: Cytomegalovirus retinitis after initiation of highly active antiretroviral therapy. Lancet 1997, 349:1443-1445.

82. Mayo J, Collazos J, Martinez E: Progressive multifocal leukoencephalopathy following initiation of highly active antiretroviral therapy. AIDS 1998, 12:1720-1722.

83. Kotecha N, George MJ, Smith TW, et al.: Enhancing progressive multifocal leukoencephalopathy: an indicator of improved immune status? Am J M ed 1998, 105:541-543.

84. Tantisi riwat $\mathrm{W}$, Tebas $\mathrm{P}$, Clifford DB, et al.: Progressive multifocal leukoencephalopathy in patients with AIDS receiving highly active antiretroviral therapy. Clin Infect D is 1999, 28:1152-1154.

85. Collazos J, Mayo J, Martinez E, Blanco MS: Contrast-enhancing progressive multifocal leukoencephalopathy as an immune reconstitution event in AIDS patients. AIDS 1999, 13:1426-1428.

86. Giudici B, Vaz B, Bossolasco S, et al.: Highly active antiretroviral therapy and progressive multifocal leukoencephalopathy: effects on cerebrospinal fluid markers of JC virus replication and immune response. Clin Infect D is 2000, 30:95-99.

87. De Luca A, Giancola ML, Ammassari A, et al.: The effect of potent antiretroviral therapy and JC virus load in cerebrospinal fluid on clinical outcome of patients with AIDSassociated progressive multifocal leukoencephalopathy. J Infect Dis 2000, 182:1077-1083.

88. Miralles $\mathrm{P}$, Berenguer J, Lacruz $\mathrm{C}$, et al.: Inflammatory reactions in progressive multifocal leukoencephalopathy after highly active antiretroviral therapy. AID S 2001, 15:1900-1902.

89. Safdar A, Rubocki RJ, Horvath JA, et al.: Fatal immune restoration disease in human immunodeficiency virus type 1-infected patients with progressive multifocal leukoencephalopathy: impact of antiretroviral therapy-associated immune reconstitution. Clin Infect D is 2002, 35:1250-1257.

90. Hoffmann C, Horst HA, Albrecht H, Schlote W: Progressive multifocal leucoencephalopathy with unusual inflammatory response during antiretroviral treatment. J $\mathrm{N}$ eurol $\mathrm{N}$ eurosurg Psychiatry 2003, 74:1142-1144.

91. Albrecht $H$, Hoffmann $C$, Degen $O$, et al.: Highly active antiretroviral therapy significantly improves the prognosis of patients with HIV-associated progressive multifocal leukoencephalopathy. AIDS 1998, 12:1149-1154.

92. Puoti M, Torti C, Ripamonti D, et al.: Severe hepatotoxicity during combination antiretroviral treatment: incidence, liver histology, and outcome. J Acquir Immune D efic Syndr 2003, 32:259-267.

93. Sulkowski MS, Thomas DL, Chaisson RE, Moore RD: Hepatotoxicity associated with antiretroviral therapy in adults infected with human immunodeficiency virus and the role of hepatitis C or B virus infection. JAM A 2000, 283:74-80.

94. Wit FW, Weverling GJ, Wed J, et al.: Incidence of and risk factors for severe hepatotoxicity associated with antiretroviral combination therapy. J Infect D is 2002, 186:23-31.

95. Puoti $M$, Gargiulo F, Roldan EQ, et al.: Liver damage and kinetics of hepatitis $C$ virus and human immunodeficiency virus replication during the early phases of combination antiretroviral treatment. J Infect D is 2000, 181:2033-2036.

96. Velasco M, Moran A, Tellez MJ: Resolution of chronic hepatitis $B$ after ritonavir treatment in an HIV-infected patient. N Engl J M ed 1999, 340:1765-1766.

97. Carr A, Cooper DA: Restoration of immunity to chronic hepatitis B infection in HIV-infected patient on protease inhibitor. Lancet 1997, 349:995-996.

98. Manegold C, Hannoun C, Wywiol A, et al.: Reactivation of hepatitis B virus replication accompanied by acute hepatitis in patients receiving highly active antiretroviral therapy. Clin Infect D is 2001, 32:144-148.

99. Proia LA, Ngui SL, Kaur S, et al.: Reactivation of hepatitis B in patients with human immunodeficiency virus infection treated with combination antiretroviral therapy. Am J M ed 2000, 108:249-251.
100. DrakeA, Mijch A, Sasadeusz J: Immune reconstitution hepatitis in HIV and hepatitis B coinfection, despite lamivudine therapy as part of HAART. Clin Infect D is 2004, 39:129-132.

101. Mastroianni CM, Trinchieri V, SantopadreP, et al.: Acute clinical hepatitis in an HIV-seropositive hepatitis B carrier receiving protease inhibitor therapy. AIDS 1998, 12:1939-1940.

102. John M, Flexman J, French MA: Hepatitis C virus-associated hepatitis following treatment of HIV-infected patients with HIV protease inhibitors: an immune restoration disease? AID S 1998, 12:2289-2293.

103. Zylberberg $\mathrm{H}$, Pialoux $\mathrm{G}$, Carnot $F$, et al.: Rapidly evolving hepatitis $C$ virus-related cirrhosis in a human immunodeficiency virus-infected patient receiving triple antiretroviral therapy. Clin Infect D is 1998, 27:1255-1258.

104. Pol S, Lebray P, Vallet-Pichard A: HIV infection and hepatic enzyme abnormalities: intricacies of the pathogenic mechanisms. Clin Infect D is 2004, 38(Suppl 2):S65-S72.

105. Uberti-Foppa C, De Bona A, Morsica G, et al.: Pretreatment of chronic active hepatitis $C$ in patients coinfected with HIV and hepatitis $C$ virus reduces the hepatotoxicity associated with subsequent antiretroviral therapy. J Acquir Immune D efic Syndr 2003, 33:146-152.

106. Martinez E, Gatell J, Moran Y, et al.: High incidence of herpes zoster in patients with AIDS soon after therapy with protease inhibitors. Clin Infect Dis 1998, 27:1510-1513.

107. Aldeen T, Hay P, Davidson F, Lau R: Herpes zoster infection in HIV-seropositive patients associated with highly active antiretroviral therapy. AIDS 1998, 12:1719-1720.

108. Domingo P, Torres OH, RisJ, Vazquez G: Herpes zoster as an immune reconstitution disease after initiation of combination antiretroviral therapy in patients with human immunodeficiency virus type-1 infection. Am J M ed 2001, 110:605-609.

109. Naseri A, Margolis TP: Varicella zoster virus immune recovery stromal keratitis in a patient with AIDS. Br J 0 phthalmol 2001 85:1390-1391.

110. Clark BM, Krueger RG, Price P, French MA: Compartmentalization of the immune response in varicella zoster virus immune restoration disease causing transverse myelitis. AID S 2004, 18:1218-1221.

111. Tangsinmankong N, Kamchaisatian W, Lujan-Zilbermann J, et al.: Varicella zoster as a manifestation of immune restoration disease in HIV-infected children. J Allergy Clin Immunol 2004, 113:742-746.

112. Greenspan D, Canchola AJ, MacPhail LA, et al.: Effect of highly active antiretroviral therapy on frequency of oral warts. Lancet 2001, 357:1411-1412.

113. King MD, Reznik DA, O'Daniels CM, et al.: Human papillomavirus-associated oral warts among human immunodeficiency virus-seropositive patients in the era of highly active antiretroviral therapy: an emerging infection. Clin Infect D is 2002, 34:641-648.

114. Hagensee ME, Cameron JE, Leigh JE, Clark RA: Human papillomavirus infection and disease in HIV-infected individuals. Am J M ed Sci 2004, 328:57-63.

115. Heard I, Pal efskyJM, Kazatchkine MD: The impact of HIV antiviral therapy on human papillomavirus (HPV) infections and H PV-related diseases. Antivir Ther 2004, 9:13-22.

116. Cattelan AM, Calabro ML, Aversa SM, et al.: Regression of AIDS-related Kaposi's sarcoma following antiretroviral therapy with protease inhibitors: biological correlates of clinical outcome. Eur J Cancer 1999, 35:1809-1815.

117. Lebbe C, Blum L, Pellet C, et al.: Clinical and biological impact of antiretroviral therapy with protease inhibitors on HIV-related Kaposi's sarcoma. AIDS 1998, 12:F45-F49.

118. Weir A, Wansbrough-Jones M: Mucosal Kaposi's sarcoma following protease inhibitor therapy in an HIV-infected patient. AIDS 1997, 11:1895-1896.

119. Connick E, Kane MA, White IE, et al.: Immune reconstitution inflammatory syndrome (IRIS) to Kaposi's sarcoma during potent antiretroviral therapy. Clin Infect D is 2004, In press. 
120. Rizos E, Drosos AA, IoannidisJP: Isolated intraparotid Kaposi sarcoma in human immunodeficiency virus type 1 infection. M ayo Clin Proc 2003, 78:1561-1563.

121. Price P, Morahan G, Huang D, et al.: Polymorphisms in cytokine genes define subpopulations of HIV-1 patients who experienced immune restoration diseases. AID S 2002, 16:2043-2047.

122. Price P, Keane NM, Stone SF, et al.: MHC haplotypes affect the expression of opportunistic infections in HIV patients. H um Immunol 2001, 62:157-164.

123. Stone SF, Price P, Brochier J, French MA: Plasma bioavailable interleukin-6 is elevated in human immunodeficiency virusinfected patients who experience herpesvirus-associated immune restoration disease after start of highly active antiretroviral therapy. J Infect D is 2001, 184:1073-1077.

124. Rutschmann OT, Negro F, Hirschel B, et al.: Impact of treatment with human immunodeficiency virus (HIV) protease inhibitors on hepatitis $C$ viremia in patients coinfected with HIV. J Infect D is 1998, 177:783-785.

125. BlancheP, Gombert B, Rivoal O, et al.: Uveitis due to Leishmania major as part of HAART-induced immune restitution syndrome in a patient with AIDS. Clin Infect D is 2002, 34:1279-1280.

126. Lawn SD, Wood C, Lockwood DN: Borderline tuberculoid leprosy: an immune reconstitution phenomenon in a human immunodeficiency virus-infected person. Clin Infect $D$ is 2003, 36:e5-e6.

127. Collazos J, Ojanguren J, Mayo J, et al.: Lymphoma developing shortly after the onset of highly active antiretroviral therapy in HIV-infected patients. AIDS 2002, 16:1304-1306.

128. Mirmirani P, Maurer TA, Herndier B, et al.: Sarcoidosis in a patient with AIDS: a manifestation of immune restoration syndrome. J Am Acad Dermatol 1999, 41:285-286.

129. Piliero PJ, Fish DG, Preston S, et al.: Guillain-Barre syndrome associated with immune reconstitution. Clin Infect D is 2003, 36:ell1-ell4.

130. Jubault V, PenfornisA, Schillo F, et al.: Sequential occurrence of thyroid autoantibodies and Graves' disease after immune restoration in severely immunocompromised human immunodeficiency virus-1-infected patients. ] Clin Endocrinol M etab 2000, 85:4254-4257.
131. Sereti I, Sarlis NJ, Arioglu E, et al.: Alopecia universalis and Graves' disease in the setting of immune restoration after highly active antiretroviral therapy. AIDS 2001, 15:138-140.

132. French MA, Lewin SR, Dykstra C, et al.: Graves' disease during immune reconstitution after highly active antiretroviral therapy for HIV infection: evidence of thymic dysfunction. AIDS Res H um Retroviruses 2004, 20:157-162.

133. SilvestreJF, Albares MP, Ramon R, Botella R: Cutaneous intolerance to tattoos in a patient with human immunodeficiency virus: a manifestation of the immune restoration syndrome. Arch D ermatol 2001, 137:669-670.

134. Fox PA, Barton SE, Francis N, et al.: Chronic erosive herpes simplex virus infection of the penis, a possible immune reconstitution disease. HIV M ed 1999, 1:10-18.

135. Nolan RC, Chidlow G, French MA: Parvovirus B19 encephalitis presenting as immune restoration disease after highly active antiretroviral therapy for human immunodeficiency virus infection. Clin Infect D is 2003, 36:1191-1194.

136. Abino JF, Peraldi $\mathrm{R}$, Lepidi $\mathrm{H}$, et al.: Bacillary splenitis (Bartonella henselae) during immune restoration in an HIV-infected patient. AIDS 2002, 16:1429-1430.

137. Bouscarat F, Maubec E, Matheron S, Descamps V: Immune recovery inflammatory folliculitis. AIDS 2000, 14:617-618.

138. Berry A, Abraham B, Dereure J, et al.: Two case reports of symptomatic visceral leishmaniasis in AIDS patients concomitant with immune reconstitution due to antiretroviral therapy. Scand J Infect D is 2004, 36:225-227.

139. Fernando R, Miller R: Immune reconstitution eosinophilia due to schistosomiasis. Sex Transm Infect 2002, 78:76.

140. Gajdatsy AD, Tay-Kearney ML: Microsporidial keratoconjunctivitis after HAART. Clin Experiment 0 phthalmol 2001 29:327-329. 